\title{
Clinical characteristics and prognosis of patients with isolated thrombotic vs. obstetric antiphospholipid syndrome: a prospective cohort study
}

Hui Jiang ${ }^{1}$, Chu-Han Wang ${ }^{1}$, Nan Jiang ${ }^{1,2}$, Jing Li ${ }^{1,2,3}$, Chan-Yuan Wu ${ }^{1,2}$, Qian Wang ${ }^{1,2,3,4}$, Meng-Tao Li ${ }^{1,2,3,4}$, Xin-Ping Tian ${ }^{1,2,3,4}$, Jiu-Liang Zhao ${ }^{1,2,3,4^{*}}$ D, Yan Zhao ${ }^{1,2,3,4^{*}}$ and Xiao-Feng Zeng ${ }^{1,2,3,4}$

\begin{abstract}
Background: Several studies suggested that thrombotic and obstetric antiphospholipid syndromes could be independent identities, but few have systematically compared their clinical characteristics and prognosis.

Objective: The objective of this study is to identify key differences between thrombotic APS (tAPS) and obstetric APS (OAPS).

Methods: This single-center, prospective study included consecutive patients with primary antiphospholipid syndrome (APS) receiving treatment at the Peking Union Medical College Hospital during a period from 2013 to 2020.

Results: Screening of the database yielded a total of 244 women with positive antiphospholipid antibody (aPL). Among the 105 women with primary APS, 39 (37.14\%) had isolated tAPS (ItAPS), 44 (41.90\%) had isolated oAPS (IOAPS), and 9 (8.57\%) had both tAPS and tAPS+OAPS. In comparison to those with loAPS, patients with ItAPS had older age (41.92 \pm 11.97 vs. $33.16 \pm 4.22$ years, $P<0.01)$, higher rate of cardiovascular risk (at least one positive of coronary heart disease, hypertension, obesity, diabetes, and hyperlipidemia) (41.03\% vs. $6.82 \%, P<0.01)$, and higher frequency of thrombocytopenia ( $43.59 \%$ vs. $20.45 \%, P<0.05$ ). Antibody profiles were generally similar among the groups, but isolated anti- $\beta 2 \mathrm{GPI}$ positivity was more common in patients with loAPS $(52.27 \%$ vs. $17.94 \%$ for ItAPS, $P=$ 0.01). Triple aPL positivity was more common in patients with both tAPS and oAPS (66.67\% vs. $46.15 \%$ for ItAPS vs. $25 \%$ for loAPS, $P=0.022$ ). Blood homocysteine was higher in patients with ItAPS (11.20 vs. $9.90 \mu \mathrm{mol} / \mathrm{L}$ for loAPS, $P<0.05)$, but there were no differences in inflammatory markers or complements. Recurrence rate of thrombosis was higher in patients with ItAPS (33.33\% vs. 2.27\% for loAPS, $P \leq 0.001$ ) with a mean follow-up of 61 months.
\end{abstract}

Conclusion: Despite generally similar antibody and biochemical profiles, patients with ItAPS had much higher risk of recurrent thrombosis than IOAPS, supporting distinct mechanisms of pathogenesis.

Keywords: Antiphospholipid syndrome, Thrombotic, Recurrence, Obstetric, Phenotype

\footnotetext{
*Correspondence: zilpumc@sina.com; zhaoyan_pumch2002@aliyun.com

'Department of Rheumatology and Clinical Immunology, Chinese Academy

of Medical Sciences \& Peking Union Medical College, Beijing, China

${ }^{2}$ National Clinical Research Center for Dermatologic and Immunologic

Diseases, Ministry of Science \& Technology, Beijing, China

Full list of author information is available at the end of the article
}

C C The Author(s). 2021 Open Access This article is licensed under a Creative Commons Attribution 4.0 International License, which permits use, sharing, adaptation, distribution and reproduction in any medium or format, as long as you give appropriate credit to the original author(s) and the source, provide a link to the Creative Commons licence, and indicate if changes were made. The images or other third party material in this article are included in the article's Creative Commons licence, unless indicated otherwise in a credit line to the material. If material is not included in the article's Creative Commons licence and your intended use is not permitted by statutory regulation or exceeds the permitted use, you will need to obtain permission directly from the copyright holder. To view a copy of this licence, visit http://creativecommons.org/licenses/by/4.0/ The Creative Commons Public Domain Dedication waiver (http://creativecommons.org/publicdomain/zero/1.0/) applies to the data made available in this article, unless otherwise stated in a credit line to the data. 


\section{Introduction}

Based on the 2006 revised Sydney criteria, antiphospholipid syndrome (APS) is defined as prolonged positive of antiphospholipid antibody (aPL) with thrombotic and/or obstetric manifestations. Traditional aPLs include anticardiolipin antibody (ACL), anti- $\beta 2$ glycoprotein antibody (anti- $\beta 2$ GPI), and lupus anticoagulant (LA) [1, 2]. Thrombotic APS (tAPS) and obstetric APS (oAPS) share similar antibody profiles and manifestations, but may represent distinct diseases [3-5]. Specifically, antigen distribution and inflammatory status differ between the two variants [6], but comparative data on clinical features and prognosis are limited. We conducted a longitudinal study to compare clinical characteristics and antibody profiles in patients with isolated tAPS (ItAPS) vs. isolated oAPS (IoAPS). The adjusted Global AntiPhospholipid Syndrome Score (aGAPSS) conceived by Savino Sciascia et al. was used to assess thrombotic risk, combing cardiovascular risks and aPL positivity $[7,8]$.

\section{Materials and methods Patients and data}

This is a single-center, prospective cohort study. The study was based on a database at the National Clinical Research Center for Dermatologic and Immunologic Diseases (NCRC-DID) at the Peking Union Medical College Hospital and included 244 patients with prolonged positive aPL between 2013 and 2020. The NCRC-DID recorded clinical characteristics, biochemical analyses, antibody profiles, and thrombotic events every 6 months. Only women with primary APS were included in the current study. ItAPS was defined as prolonged positive aPL plus a history of thrombosis but with no characteristic obstetric complications at the time of diagnosis. IoAPS was defined as prolonged positive aPL with characteristic obstetric complications but no thrombosis history at the time of diagnosis. Patients with both tAPS and oAPS (tAPS+oAPS) at the time of diagnosis were analyzed as a separate group.

\section{Statistical methods}

Continuous variables are expressed as the mean and standard deviation (SD) or the median and quartile (Q1, Q3). Comparison between ItAPS and IoAPS was conducted using Student's $t$ test or Wilcoxon-MannWhitney test. The Kruskal-Wallis $H$ test was used to compare the three groups. Categorical variables are expressed as the number and percentage and analyzed using Fisher's exact test or chi-square test as appropriate. A log-rank test was used to compare thrombotic recurrence during follow-up. Time to recurrence was defined as the interval between diagnosis and first recurrence of thrombosis and compared using the KaplanMeier method. Cox's proportional hazards regression model was used to assess the risk factors of recurrent thromboses. $P<0.05$ (2-sided) was considered statistically significant.

\section{Results \\ Demographics and baseline laboratory results}

The database included a total of 244 patients with persistent positive aPL. One hundred thirty-nine were excluded from the final analysis: 17 with incomplete data, 77 male patients, 21 women with non-criteria APS (NCAPS), and 9 women with secondary APS. Of the remaining 120 women with primary APS, 15 patients who were lost to follow-up were also excluded. The final analysis included a total of 105 women with primary APS. Among these patients, 13 (12.38\%) had ItAPS but no history of pregnancy (these patients were not enrolled in statistical analysis), 39 (37.14\%) had ItAPS (median duration of 51 months) and pregnancy histories, 44 (41.90\%) had IoAPS (median duration of 48.5 months), and $9(8.57 \%)$ had both tAPS and oAPS (median duration of 41 months) (Fig. 1).

In comparison to patients with IoAPS, patients with ItAPS were older $(41.92 \pm 11.97$ vs. $33.16 \pm 4.22$ years for IoAPS, $P<0.001$ ) and had higher body mass index $\left(24.60 \pm 4.20\right.$ vs. $22.84 \pm 3.21 \mathrm{~kg} / \mathrm{m}^{2}$ for IoAPS, $\left.P<0.05\right)$ at baseline (Table 1). Sixteen (41.03\%) patients with ItAPS had at least one cardiovascular risk factor, whereas only 3 (6.82\%) patients with IoAPS and 3 (33.33\%) patients with tAPS+oAPS had at least one cardiovascular risk factor (ItAPS vs. IoAPS vs. tAPS+oAPS, $P=0.002$ ). No differences were found in the histories of smoking, coronary heart disease, diabetes mellitus, and hyperlipidemia among the three groups. In terms of non-criteria APS manifestations, patients with ItAPS tended to experience thrombocytopenia more frequently compared to IoAPS (43.59\% vs. $20.45 \%, P$ $=0.033$ ). Patients with tAPS +oAPS had significantly higher aGAPSS (combined with aPL, hyperlipidemia, and hypertension) vs. other groups $(P=0.001)$. Complications did not differ among the three groups.

Isolated anti- $\beta 2$ GPI positivity (negative ALC and LA) was more common in the IoAPS group $(52.27 \%$ vs. $17.94 \%$ for tAPS and $11.11 \%$ for tAPS+oAPS, $P=0.001$ ). Triple aPL positivity was more common in patients with tAPS+oAPS $(66.67 \%$ vs. $46.15 \%$ for ItAPS and $25.00 \%$ for IoAPS, $P=0.022$ ). In comparison to the IoAPS group, patients with ItAPS had higher blood homocysteine $[11.20(9.70,14.60)$ vs. $9.9(8.10,12.10) \mu \mathrm{mol} / \mathrm{L}, P<$ 0.05], but similar biochemical and antibody profiles otherwise (Table 2).

\section{Thrombotic events at diagnosis and follow-up between ItAPS and loAPS}

At the baseline, patients had 68 thrombotic events, all in patients with ItAPS. Twenty-five patients (accounting 


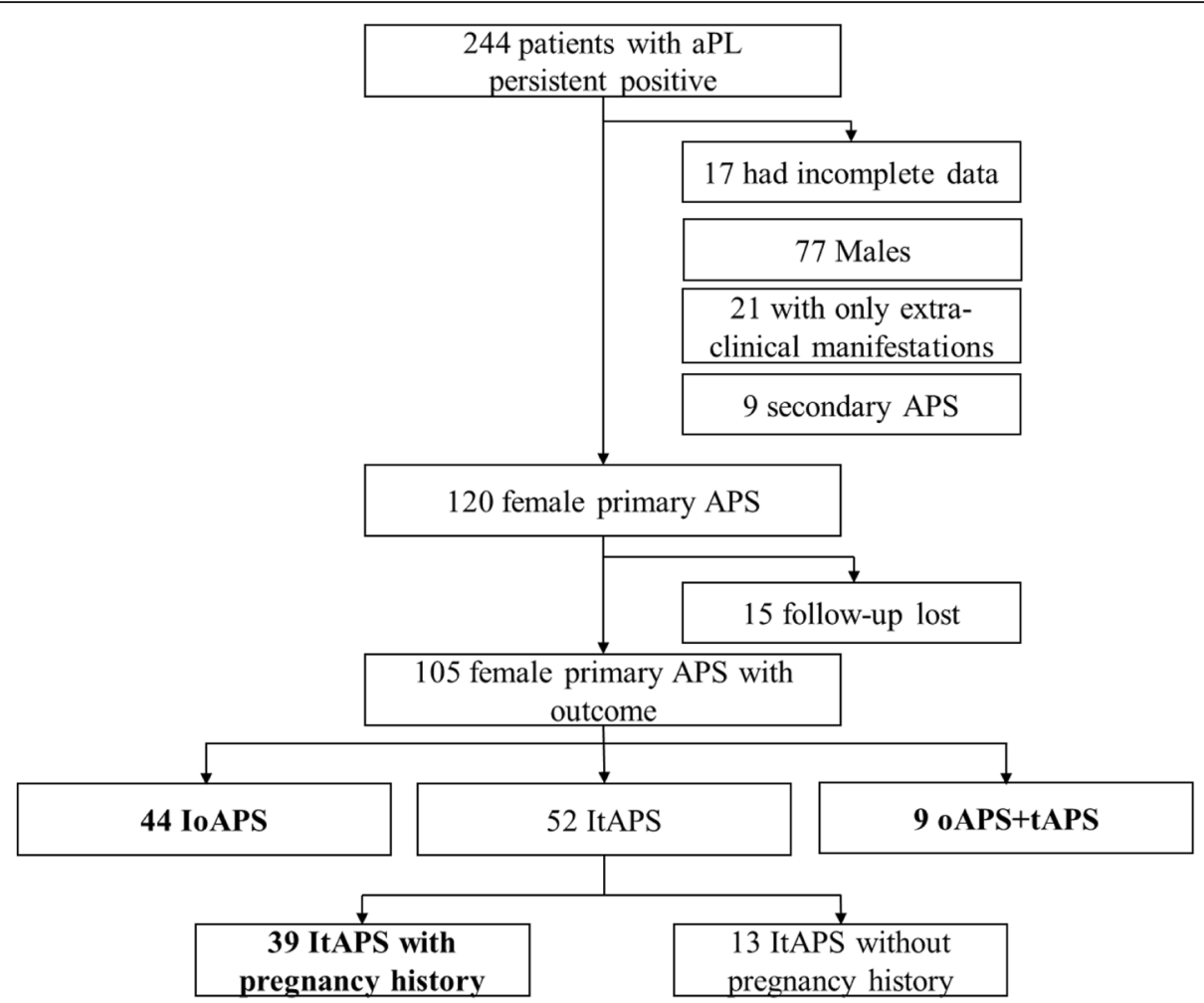

Fig. 1 APS cohort in the Peking Union Medical College Hospital database. A total of 244 patients with persistent positive of aPL were followed up, including those with primary APS, secondary APS, and non-criteria APS. After excluding 17 patients with incomplete data, 77 males, 21 patients with only extra-clinical manifestations, 9 female secondary APS patients, and 15 female primary APS lost to follow-up, a total of 105 female primary APS patients with outcome were enrolled in the cohort. Our study included 39 patients with ItAPS and pregnancy history, 44 patients with loAPS, and 9 patients with tAPS+OAPS. Patients who lacked a history of pregnancy were excluded

Table 1 Demographic characteristics

\begin{tabular}{|c|c|c|c|c|c|}
\hline & $\begin{array}{l}\text { IoAPS } \\
(n=44)\end{array}$ & $\begin{array}{l}\text { ItAPS } \\
(n=39)\end{array}$ & $\begin{array}{l}\text { tAPS+oAPS } \\
(n=9)\end{array}$ & $\begin{array}{l}P \text { value } \\
\text { All groups }\end{array}$ & $\begin{array}{l}P \text { value } \\
\text { loAPS vs. ItAPS }\end{array}$ \\
\hline Age (years), mean $\pm S D$ & $33.16 \pm 4.22$ & $41.92 \pm 11.97$ & $35.22 \pm 3.82$ & 0.000 & 0.000 \\
\hline BMI $\left(\mathrm{kg} / \mathrm{m}^{2}\right)$, mean $\pm \mathrm{SD}$ & $22.84 \pm 3.21$ & $24.60 \pm 4.20$ & $24.61 \pm 2.69$ & 0.086 & 0.024 \\
\hline Duration, months median (Q1, Q3) & $48.50(36.00,77.00)$ & $51.00(22.00,93.00)$ & $41.00(15.00,61.00)$ & 0.657 & 0.404 \\
\hline Smoking history, $n$ (\%) & $1(2.27)$ & $1(2.56)$ & 0 & 1.000 & 1.000 \\
\hline Cardiovascular risk factors, $n(\%)$ & $3(6.82)$ & $16(41.03)$ & $3(33.33)$ & 0.002 & 0.000 \\
\hline Coronary heart disease & $0(0)$ & $3(7.69)$ & 0 & 0.219 & 0.099 \\
\hline Hypertension & $1(2.27)$ & $6(15.38)$ & $2(22.22)$ & 0.028 & 0.048 \\
\hline Obesity (BMl > $\left.30 \mathrm{~kg} / \mathrm{m}^{2}\right)$ & $2(4.55)$ & $8(20.51)$ & 0 & 0.048 & 0.040 \\
\hline Diabetes mellitus & $0(0)$ & $0(0)$ & 0 & - & - \\
\hline Hyperlipidemia & $0(0)$ & $3(7.69)$ & $1(11.11)$ & 0.107 & 0.099 \\
\hline Complications, $n(\%)$ & $12(27.27)$ & $20(51.28)$ & $4(44.44)$ & 0.079 & 0.041 \\
\hline Kidney disease & $2(4.55)$ & $3(7.69)$ & 0 & 0.799 & 0.662 \\
\hline Thrombocytopenia & $9(20.45)$ & $17(43.59)$ & $4(44.44)$ & 0.056 & 0.033 \\
\hline Non-stroke CNS manifestations & $1(2.27)$ & $3(7.69)$ & 0 & 0.573 & 0.337 \\
\hline Valvular heart disease & $4(9.09)$ & $3(7.69)$ & $1(11.11)$ & 1.000 & 1.000 \\
\hline aGAPSS median (Q1, Q3) & $4(4,12)$ & $10(4,13)$ & $13(6,15)$ & 0.001 & 0.001 \\
\hline
\end{tabular}


Table 2 Laboratory test results

\begin{tabular}{|c|c|c|c|c|c|}
\hline & $\begin{array}{l}\text { IoAPS } \\
(n=44)\end{array}$ & $\begin{array}{l}\text { ItAPS } \\
(n=39)\end{array}$ & $\begin{array}{l}\text { tAPS+oAPS } \\
(n=9)\end{array}$ & $\begin{array}{l}P \text { value } \\
\text { All groups }\end{array}$ & $\begin{array}{l}P \text { value } \\
\text { loAPS vs. ItAPS }\end{array}$ \\
\hline \multicolumn{6}{|l|}{ Antibody categories } \\
\hline Triple positive, $n(\%)$ & $11(25.00)$ & $18(46.15)$ & $6(66.67)$ & 0.022 & 0.065 \\
\hline Double positive, $n(\%)$ & $7(15.90)$ & $9(23.08)$ & $1(11.11)$ & 0.678 & 0.578 \\
\hline$A C L+L A$ & $0(0)$ & $1(2.56)$ & $0(0)$ & 0.521 & 0.470 \\
\hline$L A+a n t i-\beta 2 G P I$ & $2(4.55)$ & $2(5.13)$ & $1(11.11)$ & 0.632 & 1.000 \\
\hline$A C L+a n t i-\beta 2 G P I$ & $5(11.36)$ & $6(15.38)$ & $0(0)$ & 0.651 & 0.748 \\
\hline Single positive, $n(\%)$ & $26(59.10)$ & $12(30.77)$ & $2(22.22)$ & 0.017 & 0.015 \\
\hline $\mathrm{ACL}$ & $1(2.27)$ & $1(2.56)$ & $0(0)$ & 1.000 & 1.000 \\
\hline Anti- $\beta 2 \mathrm{GPI}$ & $23(52.27)$ & $7(17.94)$ & $1(11.11)$ & 0.001 & 0.001 \\
\hline LA & $2(4.55)$ & $4(10.26)$ & $1(11.11)$ & 0.420 & 0.413 \\
\hline ESR (mm/h), median (quartile) & $10(6,27)$ & $10(5,21)$ & $11(4.5,27.5)$ & 0.814 & 0.254 \\
\hline CRP (mg/L), median (quartile) & $1.03(0.56,3.85)$ & $1.32(0.50,3.92)$ & $9.55(0.46,10.95)$ & 0.808 & 0.383 \\
\hline Hcy ( $\mu \mathrm{mol} / \mathrm{L})$, median (quartile) & $9.90(8.10,12.10)$ & $11.20(9.70,14.60)$ & $10.85(9.08,12.68)$ & 0.152 & 0.028 \\
\hline C3 (g/L), median (quartile) & $0.98(0.81,1.17)$ & $0.92(0.73,1.12)$ & $0.75(0.66,1.11)$ & 0.235 & 0.129 \\
\hline C4 (g/L), median (quartile) & $0.16(0.13,0.23)$ & $0.17(0.13,0.21)$ & $0.14(0.12,0.18)$ & 0.565 & 0.371 \\
\hline
\end{tabular}

$A C L$, anticardiolipin antibody; anti- $\beta 2 G P I$, anti- $\beta 2$ glycoprotein I antibody; $L A$, lupus anticoagulant; $E S R$, erythrocyte sedimentation rate; $C R P, C$-reactive protein; $H c y$, homocysteine; $C 3$, complement $C 3$; $C 4$, complement $C 4$

for $64.10 \%$ in patients with ItAPS) presented with arterial thrombotic events, and $23(58.97 \%)$ presented with venous thrombotic events, including 7 pulmonary embolisms, 3 myocardial infarctions, and 8 strokes (Table 3). Sixteen patients $(41.03 \%)$ had recurrent thrombosis prior to the time of diagnosis.

With the average follow-up of $61 \pm 43$ months, 13 (33.33\%) patients with ItAPS experienced new thrombotic events, 9 patients (23.08\%) had arterial thromboses, and 5 patients (10.26\%) had venous thromboses. Only 1 patient $(2.27 \%)$ with IoAPS experienced a new thrombotic event $(P<0.001$ vs. ItAPS $)$. A total of 5 patients (10.26\%), all in the ItAPS group, experienced recurrent thrombotic events during the follow-up.

\section{Survival analysis}

Kaplan-Meier analyses indicated a shorter time to first thrombotic recurrence in patients with ItAPS vs. IoAPS
$(P<0.001$; Fig. 2). In the univariate Cox regression, risk of recurrent thromboses included cardiovascular events [hazard ratio (HR) 3.316, 95\% confidence interval (CI) 1.140-9.646, $P=0.028$ ] and thromboses (HR 17.115, 95\% CI 2.237-130.927, $P=0.006$ ) (Table 4). In a multivariate Cox regression that adjusted for age, a history of isolated thrombosis was an independent risk for recurrent thromboses (HR 15.791, 95\% CI 1.747-142.763, $P=0.014$ ).

\section{Discussion}

The results from the current study demonstrated several differences between primary ItAPS and IoAPS, including age, BMI, baseline cardiovascular disease, and thrombocytopenia in demographics. Nearly one-half of the patients with ItAPS had at least one cardiovascular risk factor vs. only $6.82 \%$ in the patients with IoAPS. This is consistent with several previous studies that associated arterial thrombotic events in patients with APS with

Table 3 Thrombotic events at diagnosis and follow-up

\begin{tabular}{|c|c|c|c|c|c|}
\hline \multirow[b]{2}{*}{ Thromboses $(n)$} & \multirow{2}{*}{$\begin{array}{l}\text { Before diagnosis } \\
\text { loAPS }(n=44)\end{array}$} & \multicolumn{4}{|l|}{ Follow-up } \\
\hline & & ItAPS $(n=39)$ & loAPS $(n=44)$ & ItAPS $(n=39)$ & $P$ value \\
\hline Total thromboses, n (\%) & 0 & $39(100.00)$ & $1(2.27)$ & $13(33.33)$ & 0.000 \\
\hline Arterial thrombosis, $n$ (\%) & 0 & $25(64.10)$ & $0(0.00)$ & $9(23.08)$ & 0.001 \\
\hline Venous thrombosis, $n$ (\%) & 0 & $23(58.97)$ & $1(2.27)$ & $5(10.26)$ & 0.094 \\
\hline Pulmonary embolism, $n$ (\%) & 0 & $7(17.95)$ & $0(0.00)$ & $5(10.26)$ & 0.020 \\
\hline Myocardial infarction, $n$ (\%) & 0 & $3(7.69)$ & $0(0.00)$ & $0(0.00)$ & \\
\hline Stroke, $n(\%)$ & 0 & $8(20.51)$ & $0(0.00)$ & $1(5.13)$ & 0.470 \\
\hline Recurrent thromboses, $n$ (\%) & 0 & $16(41.03)$ & $0(0.00)$ & $5(10.26)$ & 0.020 \\
\hline
\end{tabular}




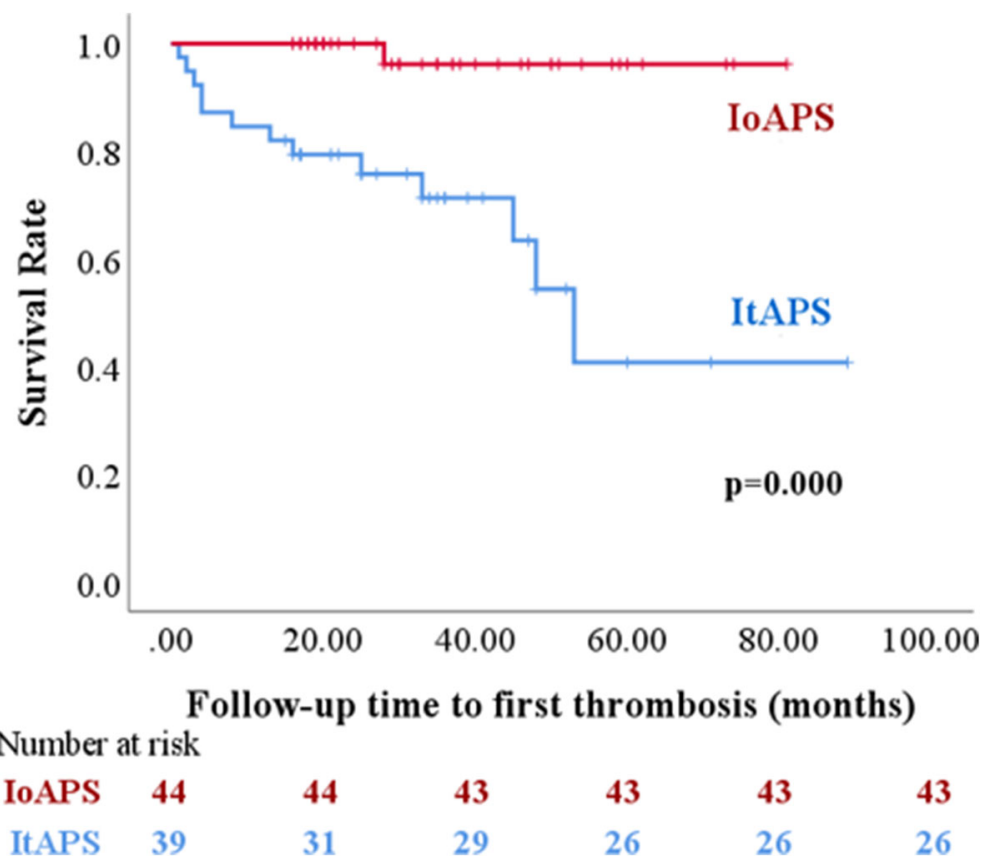

Fig. 2 Kaplan-Meier survival curves after the first thrombosis. The curve shows the time to first thrombotic recurrence during follow-up in patients with loAPS and ItAPS

traditional cardiovascular risk factors, including hypertension, diabetes, hypercholesterolemia, and smoking [9-14]. In the current study, the rate of thrombocytopenia was higher in patients with ItAPS vs. IoAPS. Such a finding is consistent with a previous study by Hisada et al., in which low platelet count was associated with increased risk of thrombotic events in aPL carriers [15].

Avivi et al. reported that $50 \%$ of patients with APS and hyperhomocysteinemia had thrombotic events [16], and Kassis et al. reported an increased risk of arterial thrombosis in patients with aPL and high homocysteine levels [17]. In the current study, the multivariate regression failed to identify increased homocysteine as a risk for recurrent thrombotic events, but subjects with ItAPS had higher blood homocysteine than IoAPS. More studies are needed to verify the potential link. Anti- $\beta 2$ GPI overexpression was associated with a high incidence of obstetric complications in previous studies $[18,19]$, while they did not compare single anti- $\beta 2$ GPI positivity between ItAPS and IoAPS. In the current study, the percentage of the patients with isolated anti- $\beta 2$ GPI positivity (negative ACL and LA) was much higher in the IoAPS group vs. in the ItAPS. The current study also found a high rate of triple aPL positivity in patients with tAPS+oAPS (66.67\%) compared to ItAPS (46.15\%) and IoAPS (25\%).

This is consistent with previous studies, in which triple aPL positivity could be a risk factor of thrombotic events [20]. In our opinion, high aGAPSS in patients with

Table 4 Univariate and multivariate Cox regression of predictors of recurrent thromboses in patients with APS

\begin{tabular}{|c|c|c|c|c|c|c|}
\hline \multirow[t]{2}{*}{ Variables } & \multicolumn{3}{|c|}{ Univariate regression } & \multicolumn{3}{|c|}{ Multivariate regression } \\
\hline & HR & $95 \% \mathrm{Cl}$ & $P$ value & HR & $95 \% \mathrm{Cl}$ & $P$ value \\
\hline ItAPS phenotype & 17.115 & $2.237-130.927$ & 0.006 & 15.791 & $1.747-142.763$ & 0.014 \\
\hline Age (per 10 years) & 0.857 & $0.417-1.762$ & 0.674 & & & \\
\hline High homocysteine level ${ }^{a}$ & 1.013 & $0.223-4.597$ & 0.987 & & & \\
\hline Cardiovascular risk & 3.316 & $1.140-9.646$ & 0.028 & & & \\
\hline Triple positive antibodies & 1.433 & $0.494-4.155$ & 0.508 & & & \\
\hline Single anti- $\beta 2$ GPI positive & 0.382 & $0.084-1.730$ & 0.212 & & & \\
\hline Thrombocytopenia & 2.030 & $0.079-5.814$ & 0.187 & & & \\
\hline
\end{tabular}

${ }^{a}$ High homocysteine level is defined as homocysteine $>15 \mu \mathrm{mol} / \mathrm{L}$

$H R$, hazard ratio; $\mathrm{Cl}$, confidence interval 
tAPS+oAPS could be partly attributed to the high rate of triple aPL positivity compared to tAPS.

Recurrent thrombosis occurred in approximately onethird of patients with ItAPS in this study, and up to $10.26 \%$ of patients with ItAPS had more than one recurrence. This is consistent with studies that recurrence thrombosis is common in patients with tAPS and rare in patients with oAPS [3, 21, 22]. Bazzan et al. reported that $31 \%$ of patients with tAPS experienced recurrent thromboses during the first 5 years after diagnosis (with or without a pregnancy, including primary APS and secondary APS) [23], and a similar study reported around $52 \%$ recurrence rate in patients with thrombotic histories (with or without a pregnancy, primary APS, including male and female), but only a $19 \%$ recurrence rate in patients with only oAPS during 18 years of follow-up [4]. Several studies reported a high risk of thrombosis in patients with oAPS [24, 25], but these studies lacked a straightforward comparison to patients with ItAPS. Although cardiovascular risks, thrombocytopenia, hyperhomocysteinemia, anti- $\beta 2 \mathrm{GPI}$, and triple aPL positivity presented a difference between ItAPS and IoAPS, the multivariate analysis failed to show an association with recurrent thrombotic events.

The mechanisms behind the distinctive prognosis in ItAPS vs. IoAPS are unknown. In the "second hit" hypothesis, positive aPL represents a prethrombotic state, and a second hit of thrombophilic conditions, such as infection, inflammation, and trauma, are needed to trigger a thrombotic event $[6,26]$. A pedigree study showed that thrombosis rarely occurs without a "second hit" [27]. Both in vivo and in vitro experiments showed that anti- $\beta 2$ GPI only binds to non-resting vascular endothelial cells (ECs), and thrombosis only forms in the presence of proinflammatory factors [28, 29]. Patients with oAPS may not require a "second hit" due to the overexpression of $\beta 2$ GPI on decidual ECs and trophoblasts [28, 30, 31]. The hormonal changes in patients with oAPS may serve as de facto "second hit" and cause placental dysfunction and abnormal vascular changes during pregnancy [6, 32, 33]. aPL may lead to different manifestations through distinct mechanisms. Lambrianides et al. reported that only aPL from patients with vascular thrombosis but no obstetric morbidity stimulates the phosphorylation of nuclear factor kappa-light-chain-enhancer of activated B cells (NFkB) and p38 mitogenactivated protein kinase and increases tissue factor activity in monocytes, thus associated with hypercoagulability in APS [34]. In vitro study by Poulton et al. showed that only aPL from patients with obstetric morbidity but no vascular thrombosis could inhibit trophoblast invasion [35]. Together, these findings may explain the higher complication rate in patients with ItAPS vs. IoAPS and the higher positive anti- $\beta 2$ GPI rate of IoAPS in our cohort. Therefore, tAPS could be categorized as an independent phenotype from oAPS both clinically and pathologically. A major strength in the current study is the exclusion of secondary APS from data analysis. Limitations include insufficient sample size and follow-up time and thus power to fully identify the differences and risk factors.

\section{Conclusions}

Differences in baseline characteristics and recurrence observed in the current study suggest ItAPS and IoAPS represent independent forms of APS.

\section{Abbreviations \\ APS: Antiphospholipid syndrome; ItAPS: Isolated thrombotic antiphospholipid syndrome; loAPS: Isolated obstetric antiphospholipid syndrome; \\ aPLs: Antiphospholipid antibodies; anti- $\beta 2$ GPI: Anti- $\beta 2$-glycoprotein antibody; tAPS: Thrombotic antiphospholipid syndrome; OAPS: Obstetric \\ antiphospholipid syndrome; NCRC-DID: National Clinical Research Center for Dermatologic and Immunologic Diseases}

\section{Acknowledgements \\ The authors thank the Department of Rheumatology at the Peking Union Medical College Hospital for providing the database.}

\section{Honorarium}

Not applicable.

\section{Authors' contributions}

HJ contributed to the statistical analysis and wrote the article. CHW contributed to the collection, supplement, and management of clinical data. $J L, C Y W, N J, M T L, Q W, X P T$, and XFZ equally contributed to the recruitment of patients. JLZ and YZ provided guidance, checked the data, and revised the content. All authors read and approved the final edition.

\section{Funding}

This study was funded by the Chinese National Key Technology R\&D Program, Ministry of Science and Technology (2017YFC0907601, 2017YFC0907602), Beijing Municipal Science \& Technology Commission (No.Z201100005520023, Z201100005520027), and CAMS Innovation Fund for Medical Science (CIFMS) (2019-12M-2-008).

Availability of data and materials

Data are available from the corresponding authors upon request.

\section{Declarations}

Ethics approval and consent to participate

The study was approved by the medical ethics committee of Peking Union Medical College Hospital and was conducted in accordance with the Declaration of Helsinki principles.

\section{Consent for publication \\ Not applicable.}

\section{Competing interests}

The authors declare that they have no competing interests.

\section{Author details}

'Department of Rheumatology and Clinical Immunology, Chinese Academy of Medical Sciences \& Peking Union Medical College, Beijing, China.

${ }^{2}$ National Clinical Research Center for Dermatologic and Immunologic Diseases, Ministry of Science \& Technology, Beijing, China. ${ }^{3}$ Key Laboratory of Rheumatology and Clinical Immunology, Ministry of Education, Beijing, China. ${ }^{4}$ State Key Laboratory of Complex Severe and Rare Diseases, Peking Union Medical College Hospital, Chinese Academy of Medical Sciences \& Peking Union Medical College, Beijing, China. 
Received: 2 October 2020 Accepted: 19 April 2021

Published online: 08 May 2021

\section{References}

1. Levine JS, Branch DW, Rauch J. The antiphospholipid syndrome. N Engl J Med. 2002;346(10):752-63.

2. Miyakis S, Lockshin MD, Atsumi T, et al. International consensus statement on an update of the classification criteria for definite antiphospholipid syndrome (APS). J Thromb Haemost. 2005;4:295-306.

3. Alijotas-Reig J, Esteve-Valverde E, Ferrer-Oliveras R, Saez-Comet L, Lefkou E, Mekinian A, et al. The European Registry on Obstetric Antiphospholipid Syndrome (EUROAPS): a survey of 1000 consecutive cases. Autoimmun Rev. 2019;18(4):406-14

4. Taraborelli M, Reggia R, Dall'Ara F, Fredi M, Andreoli L, Gerosa M, et al. Longterm outcome of patients with primary antiphospholipid syndrome: a retrospective multicenter study. J Rheumatol. 2017;44(8):1165-72.

5. Žigon P, Podovšovnik A, Ambrožič A, Tomšič M, Hočevar A, Gašperšič N, et al. Added value of non-criteria antiphospholipid antibodies for antiphospholipid syndrome: lessons learned from year-long routine measurements. Clin Rheumatol. 2019;38(2):371-8.

6. Meroni PL, Borghi MO, Grossi C, Chighizola CB, Durigutto P, Tedesco F. Obstetric and vascular antiphospholipid syndrome: same antibodies but different diseases? Nat Rev Rheumatol. 2018;14(7):433-40.

7. Radin M, Sciascia S, Erkan D, Pengo V, Tektonidou MG, Ugarte A, et al. The adjusted global antiphospholipid syndrome score (aGAPSS) and the risk of recurrent thrombosis: results from the APS ACTION cohort. Semin Arthritis Rheum. 2019;49(3):464-8.

8. Sciascia S, Radin M, Sanna G, Cecchi I, Roccatello D, Bertolaccini ML. Clinical utility of the global anti-phospholipid syndrome score for risk stratification: a pooled analysis. Rheumatology (Oxford). 2018;57(4):661-5.

9. Posch F, Gebhart J, Rand JH, Koder S, Quehenberger P, Pengo V, et al. Cardiovascular risk factors are major determinants of thrombotic risk in patients with the lupus anticoagulant. BMC Med. 2017;15(1):54.

10. AWS de Souza NS, JF de Carvalho, et al. Impact of hypertension and hyperhomocysteinemia on arterial thrombosis in primary antiphospholipid syndrome. Lupus. 2007;16:782-787.

11. Matyja-Bednarczyk A, Swadzba J, Iwaniec T, Sanak M, Dziedzina S, Cmiel A, et al. Risk factors for arterial thrombosis in antiphospholipid syndrome. Thromb Res. 2014;133(2):173-6.

12. Rodrigues CE, Bonfa E, Caleiro MT, Vendramini MB, Bueno C, Lopes JB, et al. Association of arterial events with the coexistence of metabolic syndrome and primary antiphospholipid syndrome. Arthritis Care Res (Hoboken). 2012; 64(10):1576-83.

13. Medina G, Gutierrez-Moreno AL, Vera-Lastra O, Saavedra MA, Jara LJ. Prevalence of metabolic syndrome in primary antiphospholipid syndrome patients. Autoimmun Rev. 2011;10(4):214-7.

14. Girón-González JA, García del Río E, Rodríguez C, Rodríguez-Martorell J, Serrano A. Antiphospholipid syndrome and asymptomatic carriers of antiphospholipid antibody: prospective analysis of 404 individuals. J Rheumatol. 2004;31(8):1560-7.

15. Hisada R, Kato M, Sugawara E, Fujieda Y, Oku K, Bohgaki T, et al. Thrombotic risk stratification by platelet count in patients with antiphospholipid antibodies: a longitudinal study. J Thromb Haemost. 2017;15(9):1782-7.

16. Avivi I, Lanir N, Hoffman R, Brenner B, et al. Hyperhomocysteinemia is common in patients with antiphospholipid syndrome and may contribute to expression of major thrombotic events. Blood Coagul Fibrin. 2002;13: 169-72.

17. Kassis J, Neville C, Rauch J, Busque L, Chang ER, Joseph L, et al. Antiphospholipid antibodies and thrombosis: association with acquired activated protein $C$ resistance in venous thrombosis and with hyperhomocysteinemia in arterial thrombosis. Thromb Haemost. 2004;92(6): 1312-9

18. David Faden AT, Tanzi P, et al. Anti-beta 2 glycoprotein I antibodies in a general obstetric population: preliminary results on the prevalence and correlation with pregnancy outcome. Eur J Obstet Gyn R B. 1997;73:37-42.

19. Saccone G, Berghella V, Maruotti GM, Ghi T, Rizzo G, Simonazzi G, et al. Antiphospholipid antibody profile based obstetric outcomes of primary antiphospholipid syndrome: the PREGNANTS study. Am J Obstet Gynecol. 2017;216(5):525 e1-e12.

20. Pengo V, Ruffatti A, Legnani C, Testa S, Fierro T, Marongiu F, et al. Incidence of a first thromboembolic event in asymptomatic carriers of high-risk antiphospholipid antibody profile: a multicenter prospective study. Blood. 2011;118(17):4714-8.

21. Quenby S, Farquharson RG, Dawood F, Hughes AM, Topping J. Recurrent miscarriage and long-term thrombosis risk: a case-control study. Hum Reprod. 2005;20(6):1729-32.

22. Cervera R, Khamashta MA, Shoenfeld Y, Camps MT, Jacobsen S, Kiss E, et al. Morbidity and mortality in the antiphospholipid syndrome during a 5-year period: a multicentre prospective study of 1000 patients. Ann Rheum Dis. 2009;68(9):1428-32.

23. Bazzan M, Vaccarino A, Stella S, Sciascia S, Montaruli B, Bertero MT, et al. Patients with antiphosholipid syndrome and thrombotic recurrences: a real world observation (the Piedmont cohort study). Lupus. 2016;25(5):479-85.

24. Drozdinsky G, Hadar E, Shmueli A, Gabbay-Benziv R, Shiber S. Obstetric antiphospholipid syndrome and long term arterial thrombosis risk. J Thromb Thrombolysis. 2017;44(3):371-5.

25. Gris JC, Bouvier S, Molinari N, Galanaud JP, Cochery-Nouvellon E, Mercier E, et al. Comparative incidence of a first thrombotic event in purely obstetric antiphospholipid syndrome with pregnancy loss: the NOH-APS observational study. Blood. 2012;119(11):2624-32.

26. Meroni PL, Borghi MO, Raschi E, Tedesco F. Pathogenesis of antiphospholipid syndrome: understanding the antibodies. Nat Rev Rheumatol. 2011;7(6):330-9.

27. De Angelis V, Scurati S, Raschi E, Liutkus A, Belot A, Borghi MO, et al. Proinflammatory genotype as a risk factor for aPL-associated thrombosis: report of a family with multiple anti-phospholipid positive members. J Autoimmun. 2009:32(1):60-3.

28. Agostinis C, Biffi S, Garrovo C, Durigutto P, Lorenzon A, Bek A, et al. In vivo distribution of beta2 glycoprotein I under various pathophysiologic conditions. Blood. 2011;118(15):4231-8.

29. Fischetti F, Durigutto $P$, Pellis $V$, Debeus A, Macor P, Bulla R, et al. Thrombus formation induced by antibodies to beta2-glycoprotein I is complement dependent and requires a priming factor. Blood. 2005;106(7):2340-6.

30. Mclntyre JA, Wagenknecht DR, Sugi T, et al. Phospholipid binding plasma proteins required for antiphospholipid antibody detection-an overview. Am J Reprod Immunolv. 1997;37:101-10.

31. La Rosa L, Meroni PL, Tincani A, Balestrieri G, Faden D, Lojacono A, et al. Beta 2 glycoprotein I and placental anticoagulant protein I in placentae from patients with antiphospholipid syndrome. J Rheumatol. 1994;21(9): 1684-93.

32. Abrahams VM, Chamley LW, Salmon JE. Emerging treatment models in rheumatology: antiphospholipid syndrome and pregnancy: pathogenesis to translation. Arthritis Rheumatol. 2017;69(9):1710-21.

33. Radic M, Pattanaik D. Cellular and molecular mechanisms of antiphospholipid syndrome. Front Immunol. 2018:9:969.

34. Lambrianides A, Carroll CJ, Pierangeli SS, Pericleous C, Branch W, Rice J, et al. Effects of polyclonal lgG derived from patients with different clinical types of the antiphospholipid syndrome on monocyte signaling pathways. J Immunol. 2010;184(12):6622-8.

35. Poulton K, Ripoll VM, Pericleous C, Meroni PL, Gerosa M, loannou Y, et al. Purified IgG from patients with obstetric but not lgG from non-obstetric antiphospholipid syndrome inhibit trophoblast invasion. Am J Reprod Immunol. 2015;73(5):390-401.

\section{Publisher's Note}

Springer Nature remains neutral with regard to jurisdictional claims in published maps and institutional affiliations.

Ready to submit your research? Choose BMC and benefit from:

- fast, convenient online submission

- thorough peer review by experienced researchers in your field

- rapid publication on acceptance

- support for research data, including large and complex data types

- gold Open Access which fosters wider collaboration and increased citations

- maximum visibility for your research: over $100 \mathrm{M}$ website views per year

At $\mathrm{BMC}$, research is always in progress.

Learn more biomedcentral.com/submission 